\title{
Costumbres judaizantes femeninas y transgresio- nes masculinas; análisis de las fuentes inquisitoriales en el tránsito de la Edad Media a la Moderna
}

\author{
Leonor ZOZAYA MONTES \\ Universidad Complutense de Madrid \\ lezomon@yahoo.com
}

Recibido: 20.06.2011

Aceptado: 23.01.2012

\begin{abstract}
RESUMEN
Este artículo analiza treinta y cinco procesos de fe enjuiciados en Molina de Aragón (Guadalajara) a finales de la Edad Media e inicios de la Moderna (1492-1553). En primer lugar, estudia los procesos de fe inquisitoriales finiseculares, que en su gran mayoría enjuiciaron a mujeres. Se centra en el papel de ellas en los ritos judaizantes del lugar, ya fuese sola, en grupos, o induciendo a otras compañeras a practicarlos. También investiga varios procesos de fe del siglo XVI, todos ellos de hombres. La comparación entre las acusaciones y declaraciones de ambos sexos muestra dos tendencias en la zona. Por un lado, las mujeres practicaban las típicas costumbres judaizantes (incluso auque fuesen más propias de ámbitos masculinos). Por otro lado, los hombres tendían a agredir a la religión católica imperante, así que en términos religiosos sus infracciones eran más difíciles de clasificar. Acompañando a todo ello, plantea diversas relecturas sobre las fuentes conservadas y la información que brindan, en relación con cuestiones de género, y la información que omiten.
\end{abstract}

Palabras clave: identidad, judaizantes, transgresión religiosa, fuentes inquisitoriales, Guadalajara, siglos XV-XVI.

\section{Judaizing feminine habits ana male transgresions. The analysis of the Inquistion sources during the transit from the Middle Ages to the Early Modern Age}

\begin{abstract}
Thirty five faith proceedings of law in Molina de Aragón are analyzed, dated from the end of the Middle Ages to the beginning of the Early Modern Age (1492 - 1553). First, the inquisitorial proceedings of the end of the 15th century are studied, regarding, mainly, women. An analysis is made of the role of women in judaizing rites of the place, be it in regard to isolated women, to feminine groups or for inducing women to proceed with judaization. Secondly, some other faith proceedings of law, of the 16th century, regarding men exclusively, are also studied. Comparison between accusations and declarations according to sex show that in that area women practiced typical judaizing habits (even if they should correspond more to a man's environment), whereas masculine infractions were more difficult to classify in religious terms, they tended to be very aggressive regarding the dominating Catholic Religion. Different types of readings are made regarding the sources kept and its information, related with gender differences and omission of information.
\end{abstract}

Key words: identity, judaizing habits, religious transgression, inquisitorial sources15th - 16th Cents., Guadalaxara (Spain).

1 Leonor Zozaya forma parte del Grupo de Investigación Complutense "Fuentes literarias para la Historia de las Mujeres” (nº ref: 930690), coordinadora: Cristina Segura Graíño. 


\section{INTRODUCCION}

Este artículo estudia treinta y cinco procesos de fe que enjuiciaron a parte del vecindario de la villa de Molina ${ }^{2}$. La mayoría de ellos, treinta y dos, son de finales del siglo XV. El resto, tres, se sitúan cronológicamente en la primera mitad del siglo $\mathrm{XVI}^{3}$.

La villa de Molina pertenece a la provincia de Guadalajara (en la actual Castilla-La Mancha). Se denomina Molina de Aragón porque formó parte de dicha corona durante algunos años de la Edad Media. Se sitúa en el centro de El Señorío de Molina, en cuyo derredor estaban los cuatro sexmos en que se dividía el señorío: el sexmo del Campo, el de El Pedregal, el de la Sierra y el del Sabinar ${ }^{4}$.

El foco judío de la provincia de Guadalajara fue uno de los más importantes del centro de la Península Ibérica entre los siglos XI al XVI. Al parecer, el núcleo de la villa del Señorío de Molina era el más destacado del noreste de Guadalajara en el siglo $\mathrm{XV}^{5}$. Su aljama y sus sinagogas dejan latente la gran predicación hebrea. Hoy día el barrio de la judería y el de la morería siguen conservando su antigua configuración.

Las juderías, como se sabe, tenían una razón de ser. Los Reyes Católicos, en su programa político, habían intentado apartar a los hebreos en juderías y promover el funcionamiento de la Inquisición. La finalidad era, según las fuentes oficiales, remediar el peligroso contagio que el judaísmo transmitía al catolicismo ${ }^{6}$. Por ello, en el año 1492, los monarcas dictaminaron la expulsión de los judíos del Reino.

2 Todos los reos enjuiciados en el decenio de 1490 aquí estudiados eran vecinos de la villa de Molina, salvo los enjuiciados que se detallan a continuación en el texto y sus notas correspondientes, y excepto una vecina era de la villa de Milmarcos (en el norte de Molina, pertenece al sexmo del Campo; Archivo Histórico Nacional (AHN), Inquisición, Legajo 1930, Proceso contra Inés Bernal, $n^{\circ}$ 2. Hay un caso cuya procedencia plantea dudas: Pero Bernal era vecino de Molina, pero las fuentes unas veces dicen "de Albillos” y otras “del albollón”. AHN, Inquisición, Leg. 1930, Proceso contra Pero Bernal, n 4. "Del albollón” aludiría al barrio donde residía en Molina, que se situaría en la parte donde estaba el albollón, es decir, el albañal o desaguadero. “Albillos” indicaría su procedencia originaria, Albillos, de la comarca de Burgos (a 14 kilómetros de Burgos capital). También caben ambas opciones: Pero Bernal, residente en el barrio del albollón (Molina), era natural de Albillos (Burgos).

3 Abordé parcialmente los procesos de fe que constan en este artículo anteriormente, con un enfoque diferente, en L. ZOZAYA MONTES (2009: 161-186). Aprovecho para agradecer al doctor K. Ingram las sugerencias bibliográficas.

${ }^{4}$ La posición central de Molina hoy día hace que sea un nudo gordiano en las comunicaciones de la provincia, lo cual facilita los contactos y las influencias externas, Á. NAVARRO MADRID (1981). Me atrevo a afirmar que en el pasado sucedería igual.

5 Vid. F. CANTERA BURGOS; C. CARRETE PARRONDO (1975: 3, 45-51); J. CASTAÑO (1994); J. SANZ Y DÍAZ (1982: 95-100).

${ }^{6}$ Es sabido que en las cortes celebradas en la Ciudad de Toledo en 1480, mandaron "apartar los dichos judíos en todas las ciudades y villas y lugares de los nuestros reinos y señoríos en las juderías y lugares apartados donde viviesen y morasen, esperando que con su apartamiento se remediaría; otrosí, habemos procurado y dado orden como se hiciese inquisición en los dichos nuestros reinos, la cual, como sabéis, ha 
Argumentaron que había malos cristianos que judaizaban y apostataban, debido al contacto con los judíos, así como a la "participación, conversación y comunicación” con ellos7. Fuese o no así, hubo en la Molina finisecular varias familias conversas que judaizaban, así como algunas moriscas.

En esa difusión de las tradiciones judaicas jugaron un papel fundamental las mujeres, como confirma el caso de Molina aquí estudiado. Es un hecho comprensible, dado que, según han señalado los tratadistas ${ }^{8}$, ellas estaban más apegadas a las tradiciones religiosas que los hombres, ellas conservaban más las costumbres judías $^{9}$. Las transmitían principalmente en el entorno hogareño ${ }^{10}$. A ello contribuía que frecuentemente permanecían en su domicilio ${ }^{11}$. Las educaban sus madres en los deberes religiosos y en las tareas domésticas, que estaban estrechamente vinculadas ${ }^{12}$. Es conocido su papel de portadora de tradiciones tales como limpiar la casa el viernes o prender los candiles para que estuvieran encendidos el sábado ${ }^{13}$.

Este artículo muestra esas prácticas e incide en otras que se dieron en la comunidad femenina de Molina, donde destaca su labor consistente en inducir y enseñar a otras mujeres a seguir sus rituales. También se estudia la participación de la mujer en actos y espacios que los tratadistas relacionan normalmente con las esferas masculinas. Las actitudes judaizantes que practicaba esa generación de fin de siglo, (representada principalmente por mujeres en este sondeo), y la siguiente (representada aquí únicamente por hombres), fueron cambiando a lo largo del tiem-

más de doce años que se ha hecho y hace, y por ello se han hallado muchos culpantes [...]”. Se ha manejado esta reedición de la NUEVA RECOPILACIÓN: Tomo quinto de las Leyes de Recopilación, que contiene los libros séptimo y octavo (1776, libro 8, título 2, ley 2: 438).

7 La versión oficial decía que los monarcas habían sido informados de que "había algunos malos cristianos que judaizaban y apostataban de nuestra santa fe católica, de lo cual era mucha causa la comunicación de los judíos con los cristianos”. Alegaron que los judíos habían apartado de la fe a muchos fieles atrayéndoles a sus ritos, instruyéndoles en las ceremonias, enseñándoles sus creencias, oraciones, y su Historia para que guardasen la ley de Moisés. Todo ello según constaba por "muchos dichos y confesiones". Pragmática dada en Granada, el 30 de marzo de 1492. NUEVA RECOPILACIÓN (1776, libro 8, título 2, ley 2: 438-442). La pragmática fue dada el 30 de marzo de 1492, y el tiempo para irse abarcaba hasta finales del mes de julio de 1492 inclusive. Hasta entonces estaban protegidos; después, si permaneciesen en el reino, se les castigaría con la pena de muerte. NUEVA RECOPILACIÓN (1776, libro 8, título 2, ley 2: 440-442).

8 Sobre las mujeres judías en general, véase M. J. FUENTES (2010).

9 E. CANTERA MONTENEGRO (1989: 62).

10 M. I. PÉREZ DE COLOSÍA RODRÍGUEZ (2007: 425).

11 Es conocida la importancia de la mujer en la casa. Por ejemplo, en Andalucía, según Fernando de Pulgar, las mozas de entre diez y veinte años, "desde que nacieron nunca de sus casas salieron ni oyeron ni supieron otra doctrina si no la que vieron hacer a sus padres de sus puertas adentro", F. CANTERA BURGOS (1994: 308). Sobre la importancia mujer como criptojudía en la España Moderna, véase R. LEVINEMELAMMED (1999:166). También, R. LEVINE-MELAMMED (2009: 105-106).

12 E. CANTERA MONTENEGRO (1989: 48).

13 "As with the dietary restrictions of kashrut and other Jewish ritual practices involving the maintenance of the house, such as cleaning the house on Friday or lighting oil lamps for the Sabbath, women were again portrayed as the primary figures maintaining and perpetuating Jewish traditions". G. STARR-LEBEAU (2003: 73). 
po. Se redujeron notablemente, quedó sólo representada por hombres que, lejos de judaizar, atacaban al cristianismo, de forma que se desviaban de la ortodoxia oficial. Ello se deduce de las acusaciones inquisitoriales y sus confesiones.

\section{FUENTES INQUISITORIALES SOBRE COSTUMBRES JUDAIZANTES EN LA MOLINA FINISECULAR}

En la Molina del último decenio del siglo XV había un grupo importante de conversos judaizantes, formado principalmente por mujeres. Así lo confirman algunas menciones coevas de las fuentes primarias ${ }^{14}$, lo cual se corrobora con el número de causas de fe analizadas: once hombres frente a veintiuna mujeres.

Sin embargo, ha de tenerse en cuenta que las fuentes conservadas pueden estar ofreciendo sesgos históricos. Adviértase que este artículo se basa un el conjunto de procesos conservados en una sección del Archivo Histórico Nacional, relativa a Molina de Aragón. Cabe barajar que hubiese más juicios de hombres, pero que no se hayan conservado (mientras que sí se han conservado, por cualquier causa, procesos de mujeres). No obstante, dado el papel predominante de la mujer como transmisora de las costumbres judaicas, según se explicará, se puede afirmar que en la zona y la época eran más las procesadas que los procesados. De ese modo se refleja en que hay más procesos de fe donde las protagonistas eran ellas. Sobre todo inmediatamente después de la citada expulsión de los judíos impuesta por los Reyes Católicos en 1492, cuando más puras se conservaban las tradiciones judaicas.

Del conjunto de procesos de fe conservados fechados entre 1492 y 1499, la mayoría de la gente enjuiciada fue acusada tras haber fallecido; en total, quince mujeres y nueve hombres (dos de ellos moriscos) ${ }^{15}$. Otra parte menos numerosa

14 Una judaizante llamada "la Brisela” habló de un grupo de judaizantes compuesto por doce mujeres y cuatro hombres, AHN, Inquisición, Leg. 1930, Proceso de Juana Fernández, nº 21, fols. 3rº-3vº

15 Los siguientes finados habían sido denunciados (fueron enjuiciados en los años que constan entre paréntesis). Todos pertenecen a la catalogación AHN, Inquisición, Leg. 1930: Proceso de Constanza Fernández (1494-1494), no ${ }^{0}$. Proceso de Juan Bernal "el Viejo" (1496-1497), ${ }^{\circ}{ }^{3}$. Proceso contra Pero Bernal (1496-1499), no 4. Proceso de Isabel Núñez (1496-1497), $n^{\circ} 9$. [El expediente $n^{\circ} 12$ contiene 6 procesos:] Proceso de Elvira Rodríguez (1496-1497), nº 12. Proceso de Juan Fernández "el de la puerta del baño” (1496-1497), n 12. Proceso de Mari Díaz "la Burgueña” (1496-1497), n 12. Proceso de María Fernández (1496-1497), nº 12. Proceso de García Sánchez de Huerta, clérigo (1496-1497), nº 12. Proceso de María Álvarez "la Cazorla” (1496-1497), nº 12. Proceso de Juan Fernández Greson (1493-1495), nº 14. Proceso de Aldonza Fernández (1493-1495), nº 16. Proceso de Juan Ramírez “el Ronquillo” (1496), nº 18. Proceso de Juana Rodríguez (1494-1496), $\mathrm{n}^{\circ}$ 19. Proceso de Juana Rodríguez, mujer de Ronquillo (1496), $\mathrm{n}^{\circ}$ 20. Proceso de Constanza Rodríguez (1494-1496), $\mathrm{n}^{\circ}$ 22. Proceso de doña Catalina (1492-1493), $\mathrm{n}^{\circ} 23$. Proceso de Elvira Núñez (1494-1496), n 24. Proceso de Juana Fernández “la Cohena” (1494-1496), nº 25. Proceso de Pero Fernández Fierro [o Fiero o Hierro, varía según el testimonio] (1496), nº 26. Proceso de Juan Fernández Morisco (1494-1496), n 27. Proceso de Isabel Rodríguez (1497), nº 28. Proceso de Diego Fernández Morisco (1497), nº 30. Proceso de Inés García (1497), nº 31. 
fue llamada a confesar en vida, cuatro mujeres y un clérigo ${ }^{16}$. Además, dos mujeres y el hijo de una de ellas acudieron a declarar personalmente de forma voluntaria para allegarse de nuevo al catolicismo, al menos, en teoría ${ }^{17}$. Las confesiones dadas en vida describían diversas costumbres judaicas similares a las que se detallaron en los procesos de fe de los ajusticiados cuando ya habían fallecido. De ello se deduce que muchos testimonios podrían ser verdaderos, aunque siempre cabe la duda sobre la existencia de alegatos y argumentos falsos.

Esas personas acusadas de seguir la ley de Moisés, o de ser herejes y apóstatas, habían ido creando lazos familiares (lo cual no implicaba, como es natural, que siempre mantuvieran buenas relaciones ${ }^{18}$ ). Las fuentes inquisitoriales, en parte por las abundantes notas marginales, permiten fácilmente reconstruir los grupos amistosos del lugar. Unas delaciones llamaban a otras, y los inquisidores seguían con cuita a los círculos amistosos y familiares de cada confesante ${ }^{19}$. En Molina, la mayoría de los reos se apellidaba igual y estaba emparentada. Había trece Fernández; seis García; cinco Rodríguez; cuatro Bernal; dos Núñez; un Díaz; un Álvarez ${ }^{20}$. También, otros tantos apellidos diferentes se correspondían con familias que guardaban parentesco político o consanguíneo.

El ejemplo de Isabel Rodríguez ilustra los ritos judaizantes llevados a cabo en la Molina finisecular, porque reúne muchas acusaciones de las que también fueron objeto sus convecinos. Isabel era mujer de Garci Gallego. Ambos habían sido primero requeridos y luego reconciliados por el Santo Oficio. Pero en el año 1494, ya difunta, fue acusada por el fiscal de haberse hecho pasar por cristiana en vida, mientras practicaba ceremonias judaicas ${ }^{21}$. Entre las costumbres que seguía, se destacó especialmente que:

ayunó muchas y diversas veces el ayuno mayor de los judíos, no comiendo hasta la noche, salidas las estrellas, cenando carne, poniendo manteles limpios, estando descalza los tales días; holgaba los días del dicho ayuno mayor y demandaba perdón a sus mayores y daba a sus menores, a costumbre y modo judaico; guardaba

16 Fueron llamados a confesar los siguientes reos. AHN, Inquisición, Leg. 1930, Proceso de Catalina Fernández, mujer de Diego Gigante, zapatero, (1497), n 10. Proceso de Catalina García (1493-1495), ${ }^{\circ}$ 15. Proceso de Juan García Bravo, clérigo (1493-1495), n 17. Proceso de Juana Fernández "la Brisela" (1496), n² 21. Proceso de Mari Fernández (1497), nº 29.

17 Acudieron a confesar por su propio pie los siguientes enjuiciados. AHN, Inquisición, Leg. 1930, Proceso contra Inés Bernal (1492-1495), n 2. AHN, Inquisición, Leg. 1930, Proceso de Pedro Bernal, hijo de Aldonza Fernández (1492-1496), nº 7. Proceso de Aldonza Fernández (1492-1494), nº 13.

18 Por ejemplo, Hernando Verde y Pero Bernal, guardaban enemistad con su padre, Juan Bernal "el Viejo", porque a veces les demandaba dinero prestado, y a la vez reñía con ellos y criticaba su fama y honra, "por la cual causa reinó capital enemiga con los hijos del dicho Juan Bernal”. AHN, Inquisición, Leg. 1930, Proceso de Juan Bernal "el Viejo", n 3, fol. 12ro .

19 Igual sucedía en Granada, M. I. PÉREZ DE COLOSÍA RODRÍGUEZ (2007: 434).

20 Puede ser indicativo ese breve recuento, pese al juego cambiante de apellidos dado en la baja Edad Media e inicios de la Moderna.

${ }^{21}$ AHN, Inquisición, Leg. 1930, Proceso de Isabel Rodríguez, nº 28. 
los viernes en las noches y los sábados siguientes, no haciendo cosa alguna en ellos; encendía los dichos viernes en las noches candiles con muchas mechas, no los apagaba hasta que ellos de suyo se apagaban, a modo y costumbre de los judíos; inducía y enseñaba a otras personas a que ayunasen el ayuno mayor de los judíos, y cuando alguno iba o partía camino, la susodicha le daba y echaba la bendición judaica, como los judíos lo solían y acostumbraban a hacer; bañaba a las mujeres que estaban con su tiempo y las apartaba de sus maridos durante el tal tiempo; derramaba y mandaba derramar el agua de su casa cuando alguno moría en el barrio; sacaba la landrecilla de la pierna y las venas y gordura e sebo; se vestía los sábados camisas y tocas limpias por honrar y solemnizar los dichos sábados²2.

Por todo ello, fue declarada hereje, apóstata y heresiarca. Le dieron la sentencia de excomunión mayor, condenaron su memoria y fama, confiscaron sus bienes para la cámara y fisco reales. Por supuesto, declararon a sus descendientes inhábiles e incapaces para tener dignidades, beneficios eclesiásticos, seglares u oficios públicos. Mandaron desenterrar sus huesos para entregarlos a la justicia seglar con el fin de quemarlos ${ }^{23}$. Ese fallo judicial fue similar al de la mayoría de los acusados y procesados ya finados en Molina24.

Según las acusaciones y confesiones coetáneas, aquella comunidad practicaba muchos de aquellos mismos ritos judaicos asiduamente. Entre los más comunes, acostumbraban a celebrar el día del perdón (Yom Kippur), y también a hacer el ayuno mayor con los pies descalzos. Comían carne preparada según los ritos judaicos, así como otros alimentos propios preparados según las leyes dictadas por su religión. Guardaban los viernes, cuando encendían candiles para evitar prenderlos el sábado. Celebraban el Sabath, holgaban y usaban ropas, sábanas o manteles limpios. Quebraban y mandaban quebrantar fiestas católicas. Celebraban fiestas de las cabañuelas y se reunían haciendo sinagoga. Daban la bendición judaica cuando alguien partía. Derramaban el agua almacenada de los cántaros en las casas de difuntos, los bañaban y amortajaban ${ }^{25}$.

Hasta ahí podría parecer la pauta ordinaria entre los judaizantes; no obstante, en muchas de las costumbres citadas, las mujeres adquirían un protagonismo peculiar, que a continuación se estudia con mayor detenimiento.

22 Vid. el Proceso de Isabel Rodríguez, $\mathrm{n}^{\circ} 28$, en especial los fols. $4 \mathrm{r}^{\circ}-5 \mathrm{r}^{\circ}$ y $15 \mathrm{r}^{\mathrm{0}}-15 \mathrm{v}^{\circ}$.

23 AHN, Inquisición, Leg. 1930, Proceso de Isabel Rodríguez, nº 28 , fallo en fol. $15 r^{\circ}$.

24 Por cierto, sus sobrinos también fueron procesados por la inquisición más de cincuenta años después L. ZOZAYA MONTES (2009: 167-186).

25 Afirmación basada en el análisis de todos los procesos de fe. 


\section{COSTUMBRES JUDAIZANTES, REDES AMISTOSAS Y ESPACIOS FEMENINOS EN MOLINA}

En Molina, la mujer tuvo mayor protagonismo que el hombre en diversos ritos y costumbres religiosas, en que participaba de diversas formas. En algunas situaciones era la protagonista de la acción, y en otras adoptaba el rol de educadora. En numerosas ocasiones inducía a otras mujeres a practicar ritos. También los llevaban a cabo en compañía de otras féminas, y otras veces, intencionadamente a espaldas de los hombres.

Para destacar diversas costumbres femeninas dadas en el lugar, sirve de guía la confesión personal de Aldonza Fernández, una judaizante arrepentida. Había sido mujer de Pero Fernández "de la morería”26. El 18 de agosto de 1492, fue a la Inquisición para declarar voluntariamente.

Aldonza acostumbraba a inducir a otras mujeres a hacer el ayuno mayor de los judíos, y también lo practicaba en compañía de otras. En su infancia, había hecho el mayor ayuno inducida por su madre. Después, siguió haciéndolo con su amiga Juana Fernández, mujer del herrero Juan Fernández, e indujo a ayunar su nuera, Juana Rodríguez ${ }^{27}$. Igualmente, otras lo habían practicado, como Juana Fernández, "la Brisela”, quien ayunó con Juana Sánchez, mujer de Luis Sánchez²8, o Catalina Fernández hacía ayuno con Juana Lovajona ${ }^{29}$.

Aldonza Fernández, en sus declaraciones (como la recién vista), distinguía perfectamente las costumbres dadas sólo con mujeres. Por ejemplo, guardaba los viernes con su madre y sus hermanas. Ellas vestían ropas limpias muchos sábados, uso que también se había manifestado tanto entre la mayoría de las mujeres como entre algunos hombres ${ }^{30}$. Aunque la costumbre de usar ropas limpias se diese en toda la comunidad, seguramente las mujeres fuesen las encargadas de limpiar esa ropa, pues estaban dedicadas a hacer las tareas domésticas ${ }^{31}$.

26 Que en otras fuentes mencionaban como Juan de la Morería.

27 Su padre era Juan Jiménez, su madre Catalina Jiménez, sus tías Juana y Teresa Martín. AHN, Inquisición, Leg. 1930, Proceso de Aldonza Fernández, nº 13, fol. 1rº.

28 AHN, Inquisición, Leg. 1930, Proceso contra Juana Fernández “la Brisela”, nº 21, fol. 3rº.

29 AHN, Inquisición, Leg. 1930, Proceso contra Catalina Fernández, fol. 2vº.

30 Como hicieron las mujeres cuyos juicios se citan: AHN, Inquisición, Leg. 1930, Proceso de Constanza Rodríguez, $\mathrm{n}^{\circ}$ 22; AHN, Inquisición, Leg. 1930, Proceso de Isabel Núñez, $\mathrm{n}^{\circ}$ 9; AHN, Inquisición, Leg. 1930, Proceso de Catalina Fernández, n 10; AHN, Inquisición, Leg. 1930, Proceso de Elvira Rodríguez (1496-1497), nº 12; AHN, Inquisición, Leg. 1930, Proceso de María Fernández, nº 12; AHN, Inquisición, Leg. 1930, Proceso de Aldonza Fernández, 13; AHN, Inquisición, Leg. 1930, Proceso de Juana Rodríguez, mujer de Garci Rodríguez, no 19; AHN, Inquisición, Leg. 1930, Proceso de Juana Rodríguez, mujer de Ronquillo, n 20; AHN, Inquisición, Leg. 1930, Proceso de Juana Fernández, nº 25; AHN, Inquisición, Leg. 1930, Proceso de Isabel Rodríguez, nº 28. AHN, Inquisición, Leg. 1930, Proceso de fe de Diego Fernández, morisco, $n^{\circ} 30$.

31 E. CANTERA MONTENEGRO (1989: 50). 
Aldonza distinguía ciertas usanzas que hacía a las espaldas de los hombres. Por ejemplo, afirmó que encendía los candiles -acción típicamente femenina32-, especificando que lo hacía cuando su marido e hijos no estaban en la villa, o cuando podía, "sin que ellos la viesen”. Esa declaración, que acusaba sólo al grupo femenino de la familia y dejaba fuera al masculino, podría prestarse a varias lecturas. Parece que pretendía ofrecer la imagen de que ellos ignoraban sus costumbres judaizantes, cuando era falso; dos de sus vástagos las conocían. Su hijo Pero Bernal confesó judaizar, como en breve comprobaré. Conjeturando, se puede aventurar que ese intento de protección maternal acaso se relacionase con que ella temiese que "el sexo fuerte” tomase represalias tras sus confesiones, por delatarles ${ }^{33}$.

Aldonza había quebrantado y mandado quebrantar domingos y fiestas católicas. Aunque esto no era únicamente propio de las mujeres, acaso se las deba el mérito de ser las responsables de esa actitud en su comunidad, dado el papel fundamental que ellas adquirían en la educación de las costumbres judaicas. Aldonza enseñó a sus hijos a quebrar las fiestas católicas, quienes a su vez se lo enseñaron a sus descendientes. Así se desprende de la confesión de su hijo Pero Bernal, quien el 20 de agosto de 1492 declaró que había "quebrantado e mandado quebrantar a mis mozos domingos y fiestas" 34 .

Tanto la acción recién mencionada como otras costumbres fueron realizadas por Aldonza "con intención de judaizar" ${ }^{35}$. Dicho propósito era típico en esa comunidad, como hacían por ejemplo Inés Bernal, Catalina Fernández o Juana Fernández "la Brisela"36. No obstante, otras veces afirmaban que se judaizaba por ignorancia o desconocimiento, como cuando Juana Rodríguez confesó que "comió carne en cuaresma muchas veces, no creyendo que fuera pecado estando bueno"37.

32 El hombre, al menos en ocasiones, mandaba encenderlos, como AHN, Inquisición, Leg. 1930, Proceso de Juan Fernández "el de la puerta del baño" (1496-1497), nº 12, fol. 33ro-33v.

33 Pienso en esa consideración en relación con la escasez en esa comunidad de delaciones referidas a hacer el apartamiento del hombre durante los siete días de la menstruación o el baño de purificación antes de la boda. Caso dado en Isabel Rodríguez, a quien acusaron de apartar, de sus maridos, a las mujeres con la menstruación, y de bañar a las novias la noche de su boda, que "hacía la tebila”, AHN, Inquisición, Leg. 1930, Proceso de Isabel Rodríguez, $n^{\circ} 28$, fols. $4 v^{0}$ y $15 v^{\circ}$.

34 AHN, Inquisición, Leg. 1930, Proceso de Aldonza Fernández, nº 13, fol. 1vº El 20 de agosto de 1492, su hijo Pero Bernal confesó: "he quebrantado e mandado quebrantar a mis mozos domingos y fiestas", Proceso de Pedro Bernal, $n^{\circ} 7$, fol. $1 r^{\circ}$.

35 Aldonza confesó: “quebranté y mandé quebrantar fiestas y domingos” católicos “con intención de judaizar”, AHN, Inquisición, Leg. 1930, Proceso de Aldonza Fernández, nº 13, fol. 1vº. El 20 de agosto de 1492, su hijo Pero Bernal confesó: "he quebrantado e mandado quebrantar a mis mozos domingos y fiestas”, Proceso de Pedro Bernal, $\mathrm{n}^{\circ} 7$, fol. $1 \mathrm{r}^{\circ}$.

36 Así lo declararon personalmente con respecto a muchas costumbres judaizantes, por ejemplo, AHN, Inquisición, Leg. 1930, Inés Bernal (1492-1495), n² 2; AHN, Inquisición, Leg. 1930, Proceso de Catalina Fernández, nº 10; AHN, Inquisición, Leg. 1930, Proceso de Juana Fernández “la Brisela”, nº 21. También, AHN, Inquisición, Leg. 1930, Proceso de Aldonza Fernández, nº 13.

37 Declarado el 8 de agosto de 1496. AHN, Inquisición, Leg. 1930, Proceso de Juana Rodríguez, n² 20, fol. $9 \mathrm{v}^{\circ}$. 
Respecto a las costumbres alimenticias del lugar, aunque hombres y mujeres comiesen los mismos alimentos, la labor culinaria previa de preparación correspondía en la mayor parte de los casos a la mujer, dadas sus obligaciones domésticas y sus responsabilidades en la alimentación familiar. En ese sentido, Aldonza había purgado la carne y sacado la landrecilla ${ }^{38}$. Quitar las grasas, limpiar la sangre o retirar ese nervio a la carne eran algunos pasos que seguían las mujeres del lugar para prepararla conforme a los preceptos de la religión hebrea ${ }^{39}$.

Además, hay noticias de otros ritos alimenticios del mundo judío menos reflejados en los procesos de fe del lugar, referentes a cocina femenina. Constanza Fernández fue acusada en 1494, ya difunta, de haber guisado adafinas (guiso de carne, legumbres, verduras, huevos y especias, típico judío) el viernes, para tomarlo al día siguiente. También fue culpada de hacer pan sin levadura para la Pascua del pan cenceño ${ }^{40}$. En efecto, las mujeres amasaban el pan y cocinaban tanto adafinas ${ }^{41}$ como otros guisos ${ }^{42}$, el viernes para que toda la familia los consumiera el sábado ${ }^{43}$. También tomaban carne de judíos y moros, degollada siguiendo sus ritos. Aldonza justificó su consumo aduciendo que era asequible y común en Molina ${ }^{44}$. No obstante, tomó tanto esa carne como otros alimentos en días vedados por el catolicismo, aun estando sana -según recalcó-, como por ejemplo queso, leche o huevos.

Aldonza no consumía tocino ni sebo. De modo similar, Juana Rodríguez no probaba el tocino "mas decía que lo comía"45, hecho relativamente común en Molina. Había casos similares que repercutían en la alimentación de toda la familia, pues difundían sus costumbres, porque no consentían comer tocino a los de su casa. Así lo hacía Isabel Núñez, mujer de Pascual Bernal ${ }^{46}$. Tal actitud muestra una transmisión de la enseñanza judaica por parte de la mujer al resto del hogar, que estaría aprendiendo pasivamente unas pautas alimenticias.

38 AHN, Inquisición, Leg. 1930, Proceso de Aldonza Fernández, nº 13, fol. $1 v^{\circ}$.

39 Como Catalina Fernández, AHN, Inquisición, Leg. 1930, Proceso de Catalina Fernández, no 10, fol. $2 v^{\circ}$, o Constanza Rodríguez, AHN, Inquisición, Leg. 1930, Proceso de Constanza Rodríguez, nº 22, fol. $12 \mathrm{r}^{\circ}$.

40 AHN, Inquisición, Leg. 1930, n 12, fol. 3rº. La fiesta del pan cenceño recibía diversas denominaciones, tantas como el pan. M. G. DÍAZ BARÓN, F. J. PASCUAL PÉREZ, L. M. SÁNCHEZ ARAGONÉS (1992: 255-256).

41 Como guisó adafinas Catalina Fernández, AHN, Inquisición, Leg. 1930, Proceso de Catalina Fernández, $\mathrm{n}^{\circ} 10$, fol. $2 \mathrm{v}^{\circ}$.

42 AHN, Inquisición, Leg. 1930, Proceso de Inés García, nº 31, fol. 2rº.

43 AHN, Inquisición, Leg. 1930, Proceso de Juana Rodríguez, $n^{\circ} 19$, fol. $13 r^{\circ}$.

44 Aducía: "porque en la carnecería de los cristianos, por mandato de las justicias, los judíos arrendadores o físicos degollaban carneros, y lo que sobraba compraban todos los que se acercaban; y asimismo acaecía de los moros, que toda la carnecería era una”, AHN, Inquisición, Leg. 1930, Proceso de Aldonza Fernández, $\mathrm{n}^{\circ} 13$, fol. $1 \mathrm{r}^{\circ}$.

45 AHN, Inquisición, Leg. 1930, Proceso de Juana Rodríguez, $n^{\circ}$ 19, fol. $13 r^{\circ}$.

46 AHN, Inquisición, Leg. 1930, Proceso de Isabel Núñez, nº 9, fol. $17 r^{\circ}$. 
Una cosa llevaba a la otra, entonces, lo que en principio era una costumbre alimenticia, podía acabar manifestando, en ciertas coyunturas, un problema de género, y provocar desavenencias irreconciliables en núcleos familiares compuestos por diferentes religiones. Interesa destacar el caso de Mari Fernández, la mujer de Pedro Cetina, quien contó que sabía que su abuela Catalina Núñez no comía tocino. Eso, unido a que hilaba los domingos y las fiestas católicas, motivó numerosas riñas con su padre, quien finalmente la echó de casa ${ }^{47}$. Hilar era una labor practicada en Molina entre mujeres, en ambientes familiares ${ }^{48}$.

La faceta mágica y supersticiosa femenina es conocida en las comunidades judaizantes. Aldonza también había realizado ritos relacionados con la curación. Según decía, mandó “echar las gotillas, plomo y medir la cinta a mis hijas”. De nuevo diferenciaba la actitud adoptada entre ellas y sus hijos. Con éstos siguió ciertas prácticas supersticiosas. Relató que "por miedo de las brujas, ponía en la cama de los niños bragas y trébedes cerca de la cámara, y ruda [...] y un asador, porque me decían que era bueno y que no venían brujas" 49 . Las mujeres de la familia también habían practicado ritos, pues su hijo Pedro Bernal confesó que había visto a la hermana de su madre, Juana Ruiz, hacer ciertos ritos con plomo "y decía no sé qué palabras" 50 .

Los ritos fúnebres practicados tanto por Aldonza como por las mujeres de su comunidad ayudan a discernir, una vez más, diferencias de género. Los ritos más típicos en el lugar consistían en verter el agua en las casas, bañar difuntos, amortajarlos y cantar endechas. La costumbre de derramar el agua de los cántaros la hacían y mandaban hacer tanto hombres como mujeres en el lugar.

Aldonza, como tantas otras mujeres en Molina, cantaba endechas en los mortuorios. Ella las había entonado "especialmente en la muerte de mi marido, hijos e hijas”, lo cual habla de una difusión y una recepción (aunque sólo fuese pasiva) de las costumbres judaizantes en el grupo familiar y amistoso. Igualmente, Elvira Rodríguez fue acusada de que "endechaba [...] y luego decía guayas guayas"51. Éste verso se repetía con frecuencia en las delaciones y declaraciones femeninas. Inés García, quien había sido enjuiciada cuando ya era difunta, en 1497, fue acusa-

\footnotetext{
47 Ella también confesó comer carne degollada de moros. La llevó presa el santo oficio en 1497. AHN, Inquisición, Leg. 1930, Proceso de Mari Fernández, nº 29, fol. 2vº.

48 Como la propia Aldonza, AHN, Inquisición, Leg. 1930, Proceso de Aldonza Fernández, nº 13, fol. $1 r^{\circ}$.

Constanza Fernández, AHN, Inquisición, Leg. 1930, Proceso de Constanza Fernández (1494-1494), nº 1.

49 AHN, Inquisición, Leg. 1930, Proceso de Aldonza Fernández, nº 13, fol. 1rº.

50 AHN, Inquisición, Leg. 1930, Proceso de Pedro Bernal, fol. 1rº . Otro testimonio relacionado con superstición femenina era la acusación volcada sobre Elvira Rodríguez, quien al parecer dijo:

"sacadla fuera a la fermosura, buena sea su ventura”, AHN, Inquisición, Leg. 1930; Proceso de Elvira Rodríguez, fols. $29 \mathrm{r}^{\circ}-31 \mathrm{r}^{\circ}$. El uso de la cinta estaba extendido; se ha documentado para atender a las parturientas en Francia, Italia, Inglaterra y Flandes, W. CHRISTIAN (1990: 72).

51 AHN, Inquisición, Leg. 1930, Proceso de Elvira Rodríguez, fols. $29 r^{\circ}-31 r^{\circ}$.
} 
da entre otras cosas de que "endechaba a los muertos con cánticos de judíos, y en fin decía guayas guayas”52.

Aldonza, al igual que otras madres, decidía sobre cómo enterrar a sus descendientes. Cuando se le murió una hija desposada, mandó enterrarla según los ritos judaicos ${ }^{53}$. Así volvía a adquirir protagonismo la mujer en un rito tan importante como disponer la manera en que alguien iba a pasar a la otra vida. Por ejemplo, Mari Fernández tuvo un niño que falleció y, aconsejada por otras mujeres, lo llevó a las viñas, hizo un hoyo y lo enterró "con cierta solemnidad que en otras confesiones y deposiciones se contiene más por extenso" 54 . La alusión a la solemnidad acaso aluda a los ritos anteriormente citados.

Otra costumbre típica era bañar a los difuntos, labor que al parecer llevaban a cabo en Molina, según los procesos de fe, las mujeres. Aldonza no confesó bañar difuntos, pero su hijo sí confesó haber visto "bañar muertos y poner almohadillas porque se acostumbra en la villa" 55 . Varias mujeres manifestaron haber hecho esas labores. Juana Fernández, "la Brisela”, confesó a los sesenta y cinco años "que bañó a su marido cuando murió, como se usaban entre ellos”56. Inés Bernal reveló que "había bañado difuntos, amortajándolos, tomándolos y poniéndolos almohadilla [...] con intención de judaizar”57.

Aldonza, además, practicó otras ceremonias mosaicas poco frecuentes en Molina -o al menos constan menos en las fuentes-, en las cuales intentó que otras personas fueran partícipes. Confesó una costumbre judía: que "muchas veces eché en la boca y mano de difuntos dineros o jaqueses"58. Este rito tendría el fin de pagar al barquero Caronte para cruzar la Laguna Estigia para llegar a la otra vida, y no se estilaba sólo entre las féminas. Una costumbre similar fue llevada a cabo por un morisco que judaizaba, Diego Fernández, quien "no consentía enterrar a sus hijos y parientes sin que los pusiese en la boca un gramo de plata"59.

52 AHN, Inquisición, Leg. 1930, Proceso de Inés García, n 31, fol. 2rº.

53 AHN, Inquisición, Leg. 1930, Proceso de Aldonza Fernández, nº 13.

54 AHN, Inquisición, Leg. 1930, Proceso de Mari Fernández, nº 29, fol. 2vº La inhumación judía consistía en que se ponía la cabeza de quien fallecía hacia la pared, se adecentaba, se derramaba el agua de los cántaros encima y se enterraba en tierra virgen.

55 AHN, Inquisición, Leg. 1930, Proceso de Pedro Bernal, nº 7, fol. $1 \mathrm{r}^{0}$.

56 AHN, Inquisición, Leg. 1930, Proceso de Juana Fernández, nº 21, fols. 3rº -3vº.

57 AHN, Inquisición, Leg. 1930, Proceso de Inés Bernal, $\mathrm{n}^{\circ} 2$, fol. 30rº.

58 El dinero jaqués era una moneda de curso legal en Aragón durante toda la Edad Media. Esas costumbres siguieron manteniéndose durante mucho tiempo, aún en enterramientos cristianos, L. ZOZAYA MONTES (2007: 363-364).

59 AHN, Inquisición, Leg. 1930, Proceso de Diego Fernández, nº 30, fol. 3rº. Para comprender este tipo de ritos en su contexto, véase ZOZAYA MONTES (2007). Asimismo, sobre las inversiones en funerales con ritual católico, cuya práctica superaba a las demandas testamentarias, remito a ZOZAYA MONTES, L.; ZOZAYA MONTES, M. (1998): 
El 3 de octubre de 1494, Aldonza fue declarada hereje y simulada confesante. Sin embargo, decía estar muy arrepentida por sus pecados y quiso abrazarse a la religión católica. Por ello absolvieron su sentencia de excomunión mayor y la reincorporaron al abrigo de los fieles. En pena de sus delitos, fue condenada a cárcel perpetua -su casa, como se estilaba en la época- para purgar sus pecados, luciendo siempre el sambenito 60 .

Acaso pueda afirmarse que la inquisición había sido benévola con ella, pues le dio una leve condena comparada con la que le llegaría después, ya difunta, cuando el 26 de septiembre de 1525 depuso contra ella su hija Isabel Díaz, quien era entonces viuda de Pedro del Castillo61. Isabel acusó a su madre, Aldonza, de seguir haciendo muchos de los ritos confesados tras su proceso de fe.

La actuación de la hija, acorde con los objetivos de la inquisición, mostraba una actitud sumisa a los llamamientos periódicos para delatar a las familias, y una manifestación de enojo hacia la postura supuestamente falsa de la madre. Llama la atención que precisamente la denunciase una de sus hijas, a quienes la madre había intentado adoctrinar en el judaísmo. La actitud de Isabel acaso fuese una muestra de identidad desorientada que estaba aflorando en una segunda generación de conversos que se sentía, por un lado, desplazada de los ritos judaicos, y, por otro, no integrada por completo en el catolicismo, por culpa de su mancha familiar.

Desde el segundo proceso de fe, la memoria y fama de Aldonza y sus descendientes quedó estigmatizada. Fue declarada hereje en vida y muerte, apóstata, "difusora y encubridora de hereje, de secta y simulada confesante”. Tras la sentencia de excomunión mayor, fue sometida a un escarnio público aleccionador. Mandaron sacar una estatua que la representase "con un sambenito que por la una parte tenga las figuras de condenado y por la otra parte un letrero de su nombre”. Tras leer su sentencia, fue entregada a la justicia seglar 62.

Además, ordenaron exhumar sus huesos, buscándolos allá donde estuvieren enterrados para apartarlos de entre los restos cristianos, "porque aquellos que no comunicamos ni debemos comunicar siendo vivos, no los debemos de comunicar siendo muertos”. Se tenía la intención de quemarlos públicamente. Incluso mandaron quitar cualquier laude o título que tuviera la lápida de su sepultura "en manera

60 Tendría que llevar siempre, en público y en privado, encima de las vestiduras "un sambenito de buriel negro con un asta de Santo Andrés colocada, el cual dicho sambenito no lo quite hasta que se quiera ir a acostar y que no salga de la dicha cárcel excepto en las tres Pascuas del año, en que le mandamos que vaya a ver misa mayor y a comulgar”. AHN, Inquisición, Leg. 1930, Proceso de Aldonza Fernández, nº 13, fols. $10 \mathrm{v}^{0}-11 \mathrm{r}^{\circ}$.

61 AHN, Inquisición, Leg. 1930, Proceso de Aldonza Fernández, nº 13, fol. 14vº. Su segundo proceso consta en los fols. $12 \mathrm{r}^{\circ}$ a $40 \mathrm{r}^{\circ}$.

62 AHN, Inquisición, Leg. 1930, Proceso de Aldonza Fernández, nº 13, fols. 39rº a 40vº. 
que no quede memoria de ella” 63. Esa actitud fue típica de la época, pues se buscaron los huesos de varios reos para desenterrarlos y quemarlos ${ }^{64}$.

\section{OTROS RITOS TEÓRICAMENTE MASCULINOS EN QUE PARTICIPA- BA LA MUJER}

Se acaban de destacar los ritos femeninos dados en la comunidad de Molina. Sin embargo, cabe resaltar otros que, aun siendo teóricamente más propios de hombres, eran practicados por las mujeres en la villa, apropiándose, en cierto sentido, de espacios y roles masculinos. Me referiré a las fiestas de las cabañuelas, las reuniones haciendo sinagogas y a los rezos en hebraico, teóricamente típicos de hombres.

Con respecto a las fiestas de las cabañuelas y las reuniones en sinagogas, cabe recordar que la mujer estaba obligada a cumplir la ley ritual, pero era libre de seguir los mandamientos religiosos positivos a los que se veía obligado el hombre. Ella no tenía la obligación de participar en celebraciones de diversas festividades de la religión judaica. Y, en caso de que participase en oraciones comunitarias, debía estar separada de los hombres. Aunque ella, en teoría, no acostumbraba a acudir a la sinagoga 65 .

Sin embargo, desdice la teoría el caso dado en Molina de doña Juana Fernández "la Cohena", mujer de Juan Fernández Hierro. Ese apodo significa "la Sacerdotisa”, dado que cohen significa sacerdote en hebreo, y cura en árabe. Bien, pues ella, ya difunta, fue condenada por diversas acusaciones referidas a que "estuvo en cabañuelas de judíos en sus Pascuas guardando sus fiestas, y tenía lámparas encendidas en su casa, y allí venían muchos conversos herejes a hacer las ceremonias de la ley de Moisés como en sinagoga”66.

"La Cohena" no fue la única acusada de estar tanto en cabañuelas en sus pascuas, como de reunirse haciendo sinagoga con otros judíos. Es cierto que fue juzgada difunta, pero otras confesiones personales también apoyaban que era común la participación de las mujeres entre los grupos masculinos de Molina. Así lo confirma por ejemplo la declaración en vida de Juana Fernández "la Brisela”. En su confesión habló de varias costumbres religiosas en un grupo predominantemente femenino, compuesto por doce mujeres y sólo cuatro hombres:

63 AHN, Inquisición, Leg. 1930, Proceso de Aldonza Fernández, nº 13, fols. 39rº a 40vº.

64 En concreto, los de los que constan en los procesos números 1, 3, 12 (los seis reos que constan en el proceso), 14, 15, 16, 19, 20, 22, 24, 25, 26, 27, 28. Para la identificación de los reos, véanse las notas al pie 6,7 y 8.

65 E. CANTERA MONTENEGRO (1989: 47-48).

66 AHN, Inquisición, Leg. 1930, Proceso de Juana Fernández, fol. 12rº. 
Aldonza Gutiérrez, mujer de Juan Gutiérrez de la Huerta y Mari Fernández, mujer de Pero Gutiérrez de la Huerta [sic], Aldonza Fernández, mujer de Pero Bernal [...], y "la Cohena", que se llamaba doña María "la Cohena", abuela del bachiller de la morería, y la mujer de Manuel que murió en Daroca, que se llamaba Juana la de Manuel Zapatero, que murió en Daroca, y Juana Fernández “la Morisca”, mujer de Juan Fernández, morisco, y Teresa, mujer de Diego Fernández, morisco, y Fernand González y su mujer, [...], e Inés Díaz, mujer de Juan González, barbero, y María Fernández, mujer que se decía de don Jaco [...], y Diego López Truchas, y Luis Calvo y su mujer, Catalina Sánchez y Juana "la Albardera” y su marido, que no se acuerda el nombre ${ }^{67}$.

Además de encender candiles los viernes hasta que se apagaban, acostumbraban a guardar el ayuno mayor. Ella sabía que estaban practicando ritos judíos, según explicó, "porque los veía a todos ir a hacer oración al corralejo a casa de Juan Sánchez del Corral, y que iba su madre con ellos, y que los veía holgar a todos aquel día”. También aclaró que sabía que era ayuno mayor, "porque era público que no cenaban hasta la noche, y que lo tenían ya por uso cada año como feria en aquella villa, y que esto públicamente pasaba, que no se les daba nada, y que los que vivían en el Castil de Judíos venían cada sábado compuestos a ver a los de abajo, y que su madre de este testigo decía «mirad cuales vienen testas judías compuestas» [...] y que guardaban los sábados y se venían a holgar con sus parientes"68. A los de abajo posiblemente se refiera a la calle de Abajo, que aun actualmente se sitúa en la judería de Molina, donde hay también otra paralela llamada calle de Arriba.

Es interesante también comprobar que hubo varios casos de mujeres que, en vez de rezar en romance, oraban en hebreo, como supuestamente lo hacían los hombres ${ }^{69}$. Pedro Bernal confesó haber oído a la hermana de su madre (Aldonza) rezar en hebraico, ante lo cual le preguntó “¿por qué rezáis así?, e decía [ella] que eran los salmos principales”; ante lo cual, él apostillaba: "pero a mí no me parecía bien" 70 , como intentando librarse de culpa. Ese no era un hecho aislado, según el testimonio personal de doña Catalina, mujer del carnicero Gonzalo García. Ella, con setenta años confesó que a la edad de diez o doce años, su madre "mandaba rezar en judaico", y por eso ella "hacía algunas veces oraciones judaicas"71. Mari Díaz, "la Burgueña”, fue a acusada rezar "oraciones de judíos, entre las cuales decía una oración que comienza adonay adonay, cados cados, orados orados, hurtos hurtos"72.

67 Proceso de Juana Fernández, n 21, fols. $3 r^{\circ}-3 v^{\circ}$.

68 AHN, Inquisición, Leg. 1930, Proceso de Juana Fernández, nº 21, fols. 3rº-3vº

69 Es conocido que los hombres rezaban en hebreo. En el caso de Molina cabe citar a Pero Bernal (no el hijo de Aldonza, sino otro tocayo), quien "rezaba en hebraico oraciones judaicas alzando y abajando la cabeza como lo hacían los judíos”, AHN, Inquisición, Leg. 1930, Proceso de Pero Bernal, n 4, fol. 17rº.

70 AHN, Inquisición, Leg. 1930, Proceso de Pedro Bernal, fol. $1 \mathrm{r}^{\circ}$.

${ }^{71}$ AHN, Inquisición, Leg. 1930, Proceso de doña Catalina, $n^{\circ} 23$, fol. $1 v^{\circ}$.

72 AHN, Inquisición, Leg. 1930, Proceso de Mari Díaz, nº 12, fols. $34 \mathrm{r}^{\circ}-34 v^{\circ}$. 
Sin embargo, eso no sucedía normalmente en el resto de la Corona donde, al parecer, ellas rezaban en romance, por carecer de formación religiosa, y sólo los hombres oraban en hebreo ${ }^{73}$. Bien es verdad que es imprudente generalizar, por lo que habría que diferenciar entre la capacidad de la mujer de recitar unos rezos en hebreo, y el dominio de la lengua que permite hablarla o leerla, del que ellas teóricamente carecían. Las fuentes referentes a Molina no mencionan que la mujer leyese en hebreo, como tampoco lo hacían las comunidades femeninas de la época, según los tratadistas. Sí citan algunas prácticas de lectura entre los hombres, como dos hijos de Aldonza, el citado Pero Bernal y su hermano Hernando Verde ${ }^{74}$, que era lo propio en ese género.

\section{CONDUCTAS DESVIADAS DE LA ORTODOXIA CATÓLICA EN LA ÉPOCA FINISECULAR Y SU ESCASEZ DE FUENTES}

Junto con todos aquellos ritos frecuentemente practicados por ese núcleo judaizante de la Molina finisecular, también se cometieron otras transgresiones que parecen un tanto excepcionales en la época, dada su relativa ausencia en las fuentes inquisitoriales. Esa omisión puede deberse a varias razones. Aquí propongo una primera relacionada con la existencia de las delaciones falsas, y otra segunda referida a la manipulación del discurso por parte del poder inquisitorial. Véase con más detalle.

Por un lado, algunas de esas ausencias pueden ser resultado de las delaciones y declaraciones falsas. Los delatores simulados podrían moverse por cualquier impulso, como envidia o rivalidad. Sería "normal" que tendiesen a declarar que sus enemigos tenían costumbres típicas judaizantes, pues les resultarían sencillas de definir y serían fácilmente creíbles por el tribunal del santo oficio. Las clásicas acusaciones inmediatamente generarían sospecha e interrogatorios inquisitoriales que pondrían en entredicho al rival. En cambio, sería más difícil que un delator fingido empezase a crear una acusación falsa entrando en un camino difuso donde podría tropezar fácilmente con contradicciones. De esa forma no tenía muchos visos de tener éxito, pronto se acabaría descubriendo el engaño.

Por otro lado, cabe aventurar otra razón que justificaría la escasez en las fuentes ciertas declaraciones desviadas o difíciles de encasillar. Ésta podría relacionarse con que los inquisidores orientasen el discurso en una línea tradicional. Es decir, que sólo deseasen sonsacar y profundizar en las típicas costumbres heréticas (judaizantes en el caso estudiado). Así, podrían identificar a los enemigos de la religión católica y definirlos como herejes, para poder concretar una acusación y una sentencia firme. De ese modo, los inquisidores se olvidarían de indagar en

73 E. CANTERA MONTENEGRO (1989: 48).

74 AHN, Inquisición, Leg. 1930, Proceso de Pedro Bernal, fol. 1rº. 
otros testimonios insospechados, que no supieran identificar como poderosamente subversivos de la religión católica.

Teniendo en cuenta lo sugerido, se puede afirmar que, aunque los siguientes testimonios sean relativamente escasos en las fuentes primarias, acaso fuesen más normales de lo que actualmente suele pensarse. Me refiero a actitudes enfocadas a atacar a la iglesia, al catolicismo o a algunas de sus manifestaciones, en un sentido similar a los ejemplos ya mencionados de quienes quebrantaron domingos y fiestas católicas ${ }^{75}$. Esos modos de actuar representan lo que se ha denominado "excepcional normal"76. En teoría son actos denunciados como excepcionales, pero podría tratarse, en cierto modo, de trasgresiones religiosas cotidianas que posibilitaban la relativa libertad de actuación del individuo ante el quebrantamiento de la norma religiosa imperante.

Por ejemplo, Pedro Bernal, en 1492, además de confesar algunas transgresiones típicamente judaizantes (por ejemplo, comer “carne de moros y de judíos” o escuchar lecturas y rezos en hebraico a su familia), confesó haber hecho negocios de compraventa en la iglesia de Milmarcos. Con el agravante de que otros vecinos lo habían acusado de usurero. En su confesión afirmaba que, pese a su voluntad, había ofendido a los fieles. Apuntó:

Ídem digo mi culpa que estando huido de esta villa por miedo del Duque de Alburquerque, fuíme en compañía de mi hermano Hernando de [sic] e de otros a un lugar que se dice Milmarcos, e no osábamos estar en las casas del dicho lugar ni tener haciendas ni mercaderías salvo en la Iglesia del dicho lugar, en cuya dicha Iglesia algunas veces vendíamos y comprábamos mercaderías y negociábamos, no con intención de ofender de la santa Iglesia salvo por miedo de la guerra77.

En una línea ofensiva similar, se atribuyó al difunto Pedro Fernández Fierro haber dicho en vida "que renegaba del puto de Dios". Además, fue acusado de haber cometido ritos típicos judíos como cumplir sus ayunos, derramar agua de los cántaros por la casa cuando alguien moría o reunirse "en días prohibidos en conventículos reprobados donde se juntaban muchas personas y rezaban allí oraciones reprobadas de judíos” 78 .

Diego Fernández, morisco, además de judaizar con los clásicos ritos seguidos en la zona, fue acusado de que "no sabía si nuestra señora la virgen maría fue y parió virgen, y dijo asimismo que bien le llamaban marrano porque había marrado

75 AHN, Inquisición, Leg. 1930, Proceso de Aldonza Fernández, nº 13, fol. 1vº. También su hijo, AHN, Inquisición, Leg. 1930, Proceso de Pedro Bernal, $n^{\circ} 7$, fol. $1 r^{0}$.

76 A. PONS y J. SERNA (2000: 258-259, 268-269).

77 AHN, Inquisición, Leg. 1930, Proceso de Pero Bernal, $n^{\circ} 7$, fol. $1 r^{\circ}$.

78 AHN, Inquisición, Leg. 1930, Proceso de Pero Fernández Fiero, nº 26, fol. 2rº. Año 1496. 
(sic) y estado volviéndose de buena ley a mala"79. De ese modo, aunque la ignorancia podía hacerle dudar de ciertos misterios de la fe, es obvio que una virgen, como su propio nombre indica, era virgen, y no había por qué dudar de cómo se las había ingeniado para parir. Ahí subyace el ingrediente que transformaba una duda inocente en un posible ataque.

El clérigo difunto García Sánchez de Huerta, además de haber seguido ciertos ritos típicamente judaizantes, fue acusado de que cuando muchas veces estaba en misa, al alzar y consumir el cuerpo Jesucristo, "escupía tres veces la hostia y decía porfiando que no había otra cosa sino nacer y morir, y que Dios no había traído el ánima del hombre a semejanza, y que por lo que pecase e hiciese el cuerpo, el ánima no había de recibir pena" 80 . El ataque religioso era obvio.

Otro clérigo, Juan García Bravo, respondió negativamente a numerosas cuestiones que le preguntó la inquisición acusándole de apostatar y hereticar. No obstante, fue preguntado "si ha dejado alguna ostia consagrada envuelta entre los corporales sin ponerla en la custodia; dijo que podía ser que alguna vez, no queriendo comulgar algún parroquiano, dejara la otra que tenía para le dar y ponerla en la hijuela de

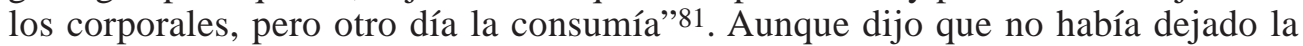
ostia en menosprecio del sacramento, finalmente fue condenado. Se le declaró hereje y apóstata, relajado, más la confiscación de todos sus bienes, por considerar que lo había hecho en menosprecio y vilipendio de la ley católica.

Interesa incidir en estas acciones anticatólicas porque guardan concomitancias con determinados modos de proceder que algunos de sus descendientes practicaron entrado el siglo XV y que mostraban un notable inconformismo religioso, como a continuación se analiza con más detalle.

\section{ACTITUDES DESVIADAS DE LOS DESCENDIENTES DE LOS CON- VERSOS DE MOLINA EN LA PRIMERA MITAD DEL SIGLO XVI}

De nuevo en la primera mitad del siglo XVI salen a colación situaciones un tanto insólitas, cuya originalidad y relativa ausencia en las fuentes no tiene porqué significar que se diesen poco en el pasado. Según se ha detallado en el apartado anterior, pueden relacionarse, entre otras cuestiones, con la escasez de delaciones falsas en este terreno (frente a costumbres típicas judaizantes) y con la manipulación del discurso por parte del poder; éste, lejos de bregar en cuestiones desviadas

\footnotetext{
79 AHN, Inquisición, Leg. 1930, Proceso de Diego Fernández, fol. 3rº.

80 Juzgado en el año 1496. AHN, Inquisición, Leg. 1930, Proceso de García Sánchez de Huerta, nº 12, fols. $36 \mathrm{r}^{0}-36 \mathrm{v}^{\circ}$.

81 AHN, Inquisición, Leg. 1930, Proceso de Pero Bernal, nº 17, fols. $1 v^{\circ}-2 r^{\circ}$.
} 
o en cierto sentido indefinidas, se centraría en indagar testimonios que le resultan más fáciles de identificar con herejías concretas como el judaísmo.

Para esta época he estudiado dos casos de descendientes de aquellos judaizantes de Molina. Pertenecían a la familia Bernal. Eran parientes y tocayos, ambos respondían al nombre de Pero Bernal. Sus juicios se dieron en la primera mitad del siglo XVI, y manifestaban una actitud religiosa distinta a la de sus predecesores. Los motivos de denuncia inquisitorial ante sus conductas desviadas de la norma tenían tintes bien diferentes, en ocasiones difíciles de definir o encasillar en términos religiosos. Parecían haber dejado atrás las prácticas judaicas. Tendían más bien a transgredir la ortodoxia dominante, a atacarla o a despreciarla, posiblemente con la intención de replicar al catolicismo.

Un vecino de Molina llamado Pero Bernal era un hombre adinerado, a quien se acusó de herejía y apostasía en el año 1523. Era hijo de Pascual Bernal, quien fue condenado, al igual que su abuelo, por seguir ritos y costumbres típicamente judaizantes $^{82}$. Los inquisidores presupusieron que su conducta se debía a que por ser “de linaje de conversos" desconocía los artículos y misterios de la fe. Sus acusadores coincidían en que, por tener antepasados judíos requeridos por la Inquisición, presumían "que no tiene verdadero conocimiento y saber de la renuncia de los artículos y misterios de nuestra santa fe" 83 .

En teoría, ese pasado converso de Pero Bernal le impedía ejercer determinados oficios que había estado desempeñando. Había sido "prioste de la Cofradía de Nuestra Señora de las Comillas y otro año fue contador de un cabildo de los caballeros y [...] fue nombrado por montaraz o escudero de guerra”. Insistía en haber conseguido licencia para desempeñarlos, mediante una habilitación del arzobispo de Sevilla. Sin embargo -según afirmaba- la Inquisición no había podido darle el documento por no tener en ese momento las llaves del archivo ${ }^{84}$.

Entre las acusaciones contra él destacaba especialmente la siguiente. Un día, cuando el clérigo y el pueblo iban en procesión, quitó la cruz a quien la portaba y la arrojó con furia a una pared, de donde cayó a un poyo (un banco de piedra adosado a la pared de una casa) y de ahí al suelo, rompiéndose. Según la declaración:

El día de la pasión de nuestro señor Jesucristo, y de la imagen y semejanza suya puesta en la cruz en memoria de nuestra redención y salvación, aconteció en los años pasados, y un día andando en procesión el clérigo y pueblo de cierto lugar, el

82 AHN, Inquisición, Leg. 1930, Proceso de Pero Bernal, nº 5; sobre su padre, vid. fol. 2vº y sobre su abuelo, vid. fol. $4 \mathrm{r}^{\circ}$.

83 AHN, Inquisición, Leg. 1930, Proceso de Pero Bernal, $n^{\circ}$ 5, fol. 4rº

84 Afirmó que Pedro Jiménez de Villena, notario del secreto, "le dijo de respuesta en las espaldas de la dicha compulsoria que no podía darle el proceso porque no tenía las llaves del [archivo] secreto”. AHN, Inquisición, Leg. 1930, Proceso de Pero Bernal, $n^{\circ}$ 5, fols. $2 v^{0}$ a $4 v^{\circ}$. 
dicho Pero Bernal tomó a una cierta persona de las manos la cruz, y sacóla del pie donde iba puesta, y con mucha furia y descaro arrojó la dicha cruz a una pared, y desde la pared cayó sobre un poyo, y desde el poyo vino a caer en el suelo de manera que el un brazo de la dicha cruz quedó arruinado al poyo, y el otro brazo en el suelo, de lo cual a la sazón se engendró y nació gran escándalo en el dicho pueblo ${ }^{85}$.

Tal comportamiento no era un hecho aislado. A finales del siglo XV, en otras zonas, como Ávila, Sigüenza y Granada, se habían dado numerosas actitudes hostiles contra el catolicismo basadas por ejemplo en maltratar crucifijos azotándolos, ensuciándolos, quemándolos o apedreándolos ${ }^{86}$.

Volviendo a la acusación de Pero Bernal, éste amenazó y atemorizó a los vecinos que sospechaba que habían acudido a la Inquisición a denunciarle, “diciendo que juraba a Dios que lo habían de pagar”. Él se dirigió especialmente a una persona con quien tenía negocios de ganado, quien había multiplicado precios para obtener mayor rentabilidad ${ }^{87}$. El 29 de julio de 1524 fue absuelto de la descomunión, pero fue condenado a cumplir ciertas penas pecuniarias (pagar cincuenta ducados de oro para gastos extraordinarios), tres meses de destierro del obispado, más las siguientes penas vejatorias:

que el primer domingo que viene ande en una procesión [...] alrededor del cementerio de la iglesia [...] en calzas y en jubón y descalzo y sin bonete y una soga de esparto al pescuezo y una vela de cera de un cuartero en las manos encendida y en ella un real; y acabada la procesión esté junto a las gradas del altar donde se diere la misa mayor según dicho es, y no se humille si no al tiempo del alce y confirmación, y acabada la misa ofrezca el real y cirio para la lumbre del Corpus Christi ${ }^{88}$.

Tocayo y pariente del anterior era Pero Bernal89, cura de Santa María de Perogómez, vecino de Molina, quien fue juzgado en 1556. Según dijo, descendía por parte de padre de cristianos viejos e hidalgos, los Escobar, aunque por parte de

85 AHN, Inquisición, Leg. 1930, Proceso de Pero Bernal, $n^{\circ}$ 5, fol. 4rº.

86 Por ejemplo, en Ávila una vecina azotó un crucifijo en 1492 porque llovía, un hombre lo azotó en 1493, y otro dijo en 1496 que no había más que nacer y morir . F. FITA COLOMÉ (1889: 335 (caso nº 38); $340\left(n^{\circ} 100\right)$ y $341\left(n^{\circ} 12\right)$ ), respectivamente. Respecto a la comarca de Sigüenza, un hombre en Atienza y otro en Sigüenza azotaron crucifijos, y otros fueron acusados de maldecir y blasfemar, J. J. CASTAÑO (1994: 317) En Granada en fechas posteriores, algunos moriscos ensuciaron, quemaron, apedrearon o quebrantaron crucifijos, J. M. GARCÍA FUENTES (1981: 18 (caso $n^{\circ}$ 3); 25 ( ${ }^{\circ}$ 59), 89 ( $\left.n^{\circ} 48\right), 91$ ( $\left.n^{\circ} 61\right)$ o $\left.103\left(n^{\circ} 16\right)\right)$.

87 AHN, Inquisición, Leg. 1930, Proceso de Pero Bernal, nº 5, fol. $4 \mathrm{r}^{\circ}$.

88 AHN, Inquisición, Leg. 1930, Proceso de Pero Bernal, $n^{\circ}$ 5, fols. $34 v^{\circ}-35 r^{\circ}$.

89 Los padres del Pero Bernal procesado en 1525 se llamaban María Núñez y Pascual Bernal. AHN, Inquisición, Leg. 1930, Pero Bernal, $n^{\circ}$ 5, fol. 2vํ. Los del Pero Bernal procesado en 1556 se llamaban Isabel Núñez y Velasco de Escobar; pero su abuelo materno se llamaba Mateo Bernal y diversos familiares suyos tenían este apellido. AHN, Inquisición, Leg. 1930, Proceso de Pero Bernal, nº 6, fols. $3 v^{\circ}$ y $4 r^{\circ}$. 
madre era "de generación de conversos”. Muchos de éstos habían sido castigados por la inquisición ${ }^{90}$.

Principalmente le imputaban delitos de desacato contra el Santo Oficio. Por lo visto, en varias ocasiones había burlado e insultado a oficiales, ministros y al presidente del Consejo de la Inquisición. Además, había fingido ser alguacil del Santo Oficio, prendiendo a ciertos individuos. En resumen, el fiscal le acusaba de:

"abatir y dar causa de vilipendio contra este dicho Santo Oficio ha tenido atrevimiento y temerosa osadía y desvergüenza en juntarse en conventículos y ayuntamientos, en los cuales se ha sentido relator de los señores del Consejo de la Santa Inquisición, y sintiendo que cierta persona de las que halló estaban era presidente del dicho Consejo, le decía haciendo burla y escarnio: «manda a vuestra señoría que relate», y comenzaba a relatar diciendo muchas injurias contra oficiales y ministros de este Santo Oficio, lo cual ha hecho muchas y diversas veces [...] y también fingió ser alguacil del Santo Oficio, cogiendo a personas y diciéndoles que estaban presos [...]"91.

En calidad de condena debería estar detenido en el Monasterio de San Francisco de Molina por dos meses y pagar diez ducados de oro para gastos extraordinarios del Santo Oficio ${ }^{92}$. Esa actitud no sólo iba contra el catolicismo. Principalmente era una muestra de disconformidad contra la Inquisición y contra las implicaciones sociales de su presencia ${ }^{93}$.

\section{CONCLUSIONES}

Este artículo se ha basado en treinta y cinco procesos de fe dados en Molina de Aragón, conservados en una sección del Archivo Histórico Nacional. En el conjunto predominan los procesos de fe de mujeres. Se podría objetar que la conservación de unas fuentes y no de otras acaso estuviese ofreciendo sesgos históricos, condicionando las investigaciones actuales. No obstante, en este caso me atrevo a afirmar que la presencia preponderante de juicios femeninos es un reflejo fiel de la

90 Según alegó el bachiller Serrano, era “de gran generación de confesos” y muchos de sus parientes habían sido "punidos y castigados” por la Inquisición. AHN, Inquisición, Leg. 1930, Proceso de Pero Bernal, $n^{\circ}$ 6, fol. $8 \mathrm{r}^{\circ}$.

91 AHN, Inquisición, Leg. 1930, Proceso de Pero Bernal, nº 6, fols. 8rº $-8 v^{\circ}$.

92 AHN, Inquisición, Leg. 1930, Proceso de Pero Bernal, $n^{\circ}$ 6. Parte de las acusaciones constan en el fol. $2 \mathrm{r}^{\circ}$, y el fallo en el fol. $18 \mathrm{r}^{\circ}$.

93 En ese sentido, cabe citar las palabras pronunciadas por un vecino de Molina que le llevaron a ser procesado en 1553, aunque salió inmune. Francisco García Bexís, guarda de los puertos, había dicho sobre algunos vecinos, ante varios testigos, que "sería bien tener la lengua cortada porque al fin no faltan malsines", refiriéndose a los soplones e informadores. El acusado se justificó aclarando que lo dijo "por los que se azotaban por este Santo Oficio”. AHN, Inquisición, Leg. 1930, Proceso de Francisco García Bexís, no 32, fols. $1 \mathrm{r}^{\circ}$ y $2 \mathrm{r}^{\circ}$. El uso la palabra malsín, de origen hebreo, no implica necesariamente que él tuviera contacto con judíos, pues era un término popular, según R. NORMAN (1991). 
proporción de enjuiciadas en Molina entre 1492 y 1499. Seguro que fueron más las enjuiciadas que los enjuiciados, pues ellas conservaban más los ritos, al educarse en el hogar, en círculos femeninos, y compartiendo espacios de reunión con otras mujeres, lo cual además era campo de cultivo para las delaciones. Mientas, el hombre frecuentaba más lugares externos al domicilio, de forma que se podía impregnar más de otras costumbres, lo cual facilitaría la pérdida de los ritos judaicos y la formación de otras actitudes más difíciles de definir.

De esos ritos femeninos finiseculares típicamente judaizantes, destacan algunos que realizaban solas y en grupo. Principalmente, inducían a otras mujeres a hacer el ayuno mayor y lo practicaban en compañía de otras, con quienes también guardaban los viernes. Encendían candiles. Quebrantaban y mandaban quebrantar domingos y fiestas católicas, y se lo enseñaban a sus mozos. Cocinaban adafinas, pan cenceño y preparaban la carne al modo judaico. Hacían prácticas mágicas o supersticiosas, que en ocasiones parecían diferenciar entre las de los hijos y las hijas. Cantaban endechas en los funerales y bañaban a los muertos. Algunas decidieron, influidas por mujeres, cómo enterrar a sus hijos, siguiendo ritos pretendidamente judaicos.

Mientras que las costumbres femeninas judaizantes eran relativamente convencionales y relativamente homogéneas, había otras que rompían un tanto el esquema. Me refiero a ciertas prácticas que se salían del patrón femenino, apropiándose en cierto sentido de espacios y roles masculinos. Por ejemplo, cuando iban a las fiestas de las cabañuelas, cuando se reunían en sinagoga con los hombres o cuando rezaban en hebraico. Caso sintomático es el representado por doña Juana Fernández, "la Cohena”, cuyo apodo significa "la Sacerdotisa".

Los procesos de fe de hombres datados a finales de siglo, además de judaizar, muestran otras transgresiones totalmente diferentes, acaso más originales, que se dejaban atrás el encuadramiento de los ritos judaicos para meterse en el ataque al catolicismo. Me refiero por ejemplo a renegar e insultar a Dios, hacer negocios de compraventa en la iglesia ofendiendo a los fieles, o escupir en la hostia sagrada.

Esas actitudes masculinas dadas a finales del siglo XV se radicalizaron en el siglo siguiente. Incluso el tono de los testimonios en las fuentes cambió. Ya no les acusaban de judaizar, sino de ser apostatas, en definitiva, por agredir a la iglesia. Posiblemente adoptasen esta postura para contestar al catolicismo, como consecuencia de su inconformismo con él y de sentirse de alguna forma vinculados a sus orígenes judíos. Incluso parece que mediante sus infracciones intentaban hacer alarde de algún tipo de conciencia colectiva orientada a demostrar que formaban un grupo aparte, una nueva identidad que quedaba fuera de los parámetros ortodoxos de las religiones.

En cualquier caso, esos testimonios dados en las fuentes inquisitoriales que son un tanto inauditas, difíciles de encorsetar en términos religiosos, escasean más que 
las anteriores (las clásicas referidas a judaizantes). Acaso esa falta se deba a que el poder inquisitorial evitaba encauzar el discurso por estas vías extravagantes, porque no le interesaría indagar informaciones difíciles de catalogar. Esa escasez también puede deberse a que las delaciones falsas serían menos en estos terrenos fangosos, pues el delator fingido tendría más posibilidades de contradecirse y de mostrar sus maliciosas artimañas.

Por todo ello, cabe deducir que cuanto más rara y original fuese una acusación (una juzgable como cierta), más probabilidades tiene de que responda a un hecho real en el pasado. Por el contrario, cuando se trata de las típicas acusaciones de judaizar, más probabilidades existen de que haya falsedad en la delación.

\section{BIBLIOGRAFÍA}

CANTERA BURGOS, F. (1994): "Fernando de Pulgar y los conversos", Sefarad: revista de estudios hebraicos, sefardíes y de Oriente Próximo, 2, pp. 295-348.

CANTERA BURGOS, F.; CARRETE PARRONDO, C. (1975): Las juderías medievales en la provincia de Guadalajara, p. 3 y pp. 45-51, Madrid

CASTAÑO, J. (1994): Las comunidades judías en el obispado de Sigüenza en la baja Edad Media: transformación y disgregación del judaísmo en Castilla a finales del Medievo, Madrid, UCM, Tesis Doctoral.

CONTRERAS, J.; PULIDO, I; BENÍTEZ, R (2005): Judíos y moriscos. Herejes. Barcelona.

CHRISTIAN, W. (1990): Apariciones en Castilla y Cataluña (siglos XIV-XVI), Madrid.

DÍAZ BARÓN, M. G.; PASCUAL PÉREZ, F. J.; SÁNCHEZ ARAGONÉS, L. M. (1992): "Modelo de vida cotidiana de los Judíos en el Valle del Ebro en el tránsito de la Edad media a la Moderna”, en IGLESIA DUARTE, J. A. DE LA (ed.): II Semana de Estudios Medievales, Logroño, Instituto de Estudios Riojanos, pp. 253-259.

FITA COLOMÉ, F. (1889): "Nuevos datos para escribir la historia de los judíos españoles”, Boletín de la Real Academia de la Historia, 15.

FUENTES, M. J. (2010): Identidad y convivencia. Musulmanas y judías en la España Medieval.

GARCÍA FUENTES, J. M. (1981), La inquisición en Granada en el siglo XVI. Fuentes para su estudio, Granada.

LEVINE-MELAMMED, R. (1999): Heretics or Daughters of Israel? The Crypto Jewish Women of Castile, Oxford, Oxford University Press.

LEVINE-MELAMMED, R. (2009): “Women in Medieval Jewish Societies”, en F. E. GREENSPAHN (ed.): Women and Judaism: New Insights and Scholarship, Nueva York, New York University Press.

NAVARRO MADRID, A. (1981): “Molina de Aragón. Estudio de Geografía Urbana”, Geographica, XXIII, pp. 181-195.

NORMAN, R. (1991), "La lengua hebrea entre los cristianos españoles medievales: voces hebreas en español”, Revista de Filología Española, 71, pp. 137-143. 
NUEVA RECOPILACIÓN: Tomo quinto de las Leyes de Recopilación, que contiene los libros séptimo y octavo, Madrid, Impr. de la Real Gaceta, 1776.

PÉREZ DE COLOSÍA RODRÍGUEZ, M. I. (2007): “Mujeres procesadas por el tribunal del Santo Oficio de Granada”, Baetica. Estudios de Arte, Geografía e Historia, 27, pp. 423-436.

PONS, A. y SERNA, J. (2000): Cómo se escribe la microhistoria. Ensayo sobre Carlo Ginzburg, Madrid.

SÁENZ BADILLOS, A (1991): Literatura Hebrea en la España Medieval, Madrid.

SANZ Y DÍAZ, J. (1982): Historia verdadera del Señorío de Molina, Guadalajara.

SEGURA GRAÍÑ̃, C. (1991): "Fuentes para hacer una historia de la religiosidad de las mujeres”, en MUÑOZ FERNÁNDEZ, A.; GRAÑA CID, M. del M. (eds.): Religiosidad femenina. Expectativas y realidades (siglos VIII-XVIII), Madrid.

STARR-LEBEAU, G. (2003): In the Shadow of the Virgin. Inquisitors, Friars and Conversos in Guadalupe, Princeton, Princeton University Press.

ZOZAYA MONTES, L.; ZOZAYA MONTES, M. (1998): “Una fuente archivística inusitada por la historiografía de la muerte en la Edad Moderna: los recibos de las limosnas”, Anexos de la Revista SIGNO, 2, pp. 257-267.

ZOZAYA MONTES, L. (2007), "El ceremonial fúnebre como medio de adscripción a la religión católica”, en: F. NÚÑEZ ROLDÁN (coord.), Ocio y Vida Cotidiana en el Mundo Hispánico (siglos XVI-XVIII), Sevilla, pp. 353-366.

ZOZAYA MONTES, L. (2009): “A Thorn in the Community: Popular Religious Practice and Converso Dissidence in the District of Molina de Aragon”, en K. INGRAM (ed.): The Conversos and Moriscos in Late Medieval Spain and Beyond. Volumne One: Departures and Changes. Colección: Studies in medieval and reformation traditions, Converso and Morisco Studies, Leyden (Holanda), Ed. Brill, pp. 161-186. 